ISSN1027-5495. Functional Materials, 25, No.2 (2018), p. 391-396

\title{
Physico-mathematical model for determining the direction in space to point sources of gamma radiation using spherical absorber
}

\author{
A.N.Grigoryev ${ }^{1}$, Z.V.Bilyk ${ }^{1}$, I.Pettersson ${ }^{2}$, Yu.V.Litvinov ${ }^{3}$, \\ N.E.Polyansky ${ }^{3}$, A.V.Sakun ${ }^{1}$, V.V.Marushchenko ${ }^{1}$, \\ I.Yu.Cherniavskyi ${ }^{1}$, E.F.Voronkin ${ }^{4}$, O.O.Sosnutska ${ }^{4}$, \\ S.Yu.Petrukhin ${ }^{1}$, S.N.Indykov ${ }^{1}$, V.E.Haydabuka ${ }^{1}$
}

${ }^{1}$ Military Institute of Tank Troops of the National Technical University "Kharkiv Polytechnic of Institute" Poltavskyi Shliakh Str., 192, Kharkiv, 61098, Ukraine

${ }^{2}$ UiT The Arctic University of Norway, Lodve Langes gate, 2, Narvik, 8505, Norway

${ }^{3}$ V. Karazin Kharkiv National University, Svobody Square 4, Kharkiv, 61022, Ukraine

${ }^{4}$ SSI “Institute for Single Crystals" Institute for Scintillation Materials National Academy of Sciences of Ukraine, Nauky Ave 60, Kharkiv, 61001, Ukraine

Received June 29, 2017

\begin{abstract}
Physico-mathematical model for determining the direction in space to point sources of gamma radiation using a spherical absorber was developed. CdTe detectors of appropriate sizes are placed in the regular pyramid tops under absorber. The physico-mathematical model allowed, taking into account the exponential attenuation of gamma radiation by the absorber, to find the distance from the location of any CdTe sensor to the surface of sphere in any direction in space. Calculated information and signal received from the detectors, correlate to each other. The ratios found depend on the angle to the source of gamma radiation and represent the ratio of transmittance coefficients for four sensors. A methodology for locating the developed device in space, which allowed to obtain dependence of the calculated ratios from the angle in space for $\theta=90^{\circ}$ and $\varphi$ from 0 to $360^{\circ}$ in increments of $15^{\circ}$ was proposed. Each direction in space corresponds to a set of six respective ratios.

Keywords: physico-mathematical model, determining the direction, detector under absorber, source of gamma radiation, spherical absorber.

Разработана физико-математическая модель определения направления на точечный источник гамма-излучения в пространстве с использованием шарообразного поглотителя. Детекторы из CdTe необходимого размера размещают в вершинах правильной пирамиды под поглотителем. Физико-математическая модель позволила с использованием экспоненциального закона ослабления гамма-излучения поглотителем найти расстояния от расположения любого $\mathrm{CdTe}$ датчика до поверхности шара в любом направлении пространства. Рассчитанную информацию-сигнал, полученную от детекторов, соотносят одну к другой. Найденные соотношения зависят от угла на источник гамма-излучения и представляют собой отношения коэффициентов пропускания для четырех датчиков. Предложена методика размещения разработанного средства в пространстве, позволяющая
\end{abstract}


получить зависимость рассчитанных соотношений от угла в пространстве для $\theta=90^{\circ}$ и $\varphi$ від $0^{\circ}$ до $360^{\circ}$ с шагом $15^{\circ}$. Каждому направлению в пространстве соответствует набор из шести соответствующих соотношений.

\begin{abstract}
Фізико-математична модель визначення напрямку у просторі на точкові джерела гамма-випромінювання 3 використанням кульового поглинача. О.М.Григор'єв, З.В.Білик, І.В.Петерсон, Ю.В.Литвинов, М.С.Полянський, О.В.Сакун, В.В.Марущенко, І.Ю.Чернявський, Є.Ф.Воронкін, О.О.Сосницька, С.Ю.Петрухін, С.М.Індиков, В.С.Гайдабука

Розроблено фрізико-математичну модель визначення напрямку на точкові джерела гамма-випромінювання у просторі 3 використанням кульового поглинача. Детектори 3 CdTe необхідного розміру розміщують у вершинах правильної піраміди під поглиначем. Фізико-математична модель дозволила з зрахуванням експоненційного ослаблення гаммавипромінювання поглиначем знаходити відстань від розташування будь-якого CdTе датчика до поверхні кулі у будь-якому напрямі у просторі. Розраховану інформацію-сигнал, що отримано від детекторів, співвідносять один до одного. Знайдені співвідношення залежать від кута на джерело гамма-випромінювання та являють собою відношення коефіцієнтів пропускання для чотирьох датчиків. Запропоновано методику розташування розробленого засобу у просторі, що дозволила отримати залежність розрахованих співвідношень від кута в просторі для $\theta=90^{\circ}$ та $\varphi$ від $0^{\circ}$ до $360^{\circ}$ з кроком $15^{\circ}$. Кожному напрямку у просторі відповідає набір з шістьох відповідних співвідношень.
\end{abstract}

\section{Introduction}

Nuclear technologies and usage of nuclear energy cause the environmental pollution by radioactive substances. In addition, there is a worldwide problem of illicit trafficking of nuclear radioactive materials and sources of nuclear smuggling, which have come out of regulated supervision and can be used for malicious purposes. This requires the creation of perfect radiation monitoring systems [1].

In known methods and equipment of accelerated search of local sources of gamma radiation, in which the angle distribution, as well as direction to the local sources of gamma radiation are determined, it is used multi-modular detecting devices (MDD) of two types - four and six-modular, which represent an absorber with partially recessed scintillation detectors or gas-discharge counter in it. The developed equipment, based on respond received from the modules, makes it possible to determine the angle to the gamma source. The disadvantage of these devices is the determination of the direction in only one plane. The author [2] developed and created the MDD models of different configurations to determine the direction to the point sources of gamma radiaion in the plane and methods of their accelerated search with a minimum error of determination of direction $\pm 2^{\circ}$. At the same time, for localization of the gamma source, according to the results of one measurement, at least two MDDs must be located at distance of $150 \mathrm{~cm}$ from each other, and the position of the gamma source must be known up to a half-space.

Analysis shows that the most effective and prospective method for determining the direc- tion to sources of gamma radiaion in space is the use of detection units based on a spherical absorber. There is a well-known device with a spherical viewing area used for searching for photonic sources [3]. It can be used for radiation monitoring to find and determine the direction to the photon source in the solid angle $4 \pi$ steradian. Detectors are located along the edges of a regular polyhedron, which is formed by an electronic transducer, inside of which there is a protective screen, and this allows to achieve the maximum sensitivity. Disadvantages of the device are the dependence of the received data on energy and dependence of the resolution on the number of detectors and electronic transducers. There is no mathematical model and practical implementation of this device for determining the direction to gamma source.

There is the application of a spherical absorber using five CdZnTe detectors for measuring the angular distribution of gamma radiation intensity. It needs to simplify the procedure for transferring the information to a computer to increase the processing speed of incoming information, because of each channel has its own memory. Also, there is no mathematical model and practical implementation of this device for determining the direction to gamma source.

The problem of determining the direction of arrival of gamma quanta using the spherical absorber was solved by the author [4] by the method of counting the difference in gammaquantum fluxes in detectors, which is result of the fact that gamma quanta have passed different paths in matter before registration by detectors. Comparison of the calculated and experimental coefficients for two detectors was made, which is the ratio of the total number 
of signals registered by one detector to the total number of signals registered by the other one, and also proposed to use three detectors to determine the direction to the point sources of gamma radiaion. The applied problem of the practical determination of the direction to the point sources of gamma radiaion by three detectors is not solved, there is no mathematical model that allows to determine the distance to the surface of the sphere for any point where the detector is located.

The purpose of this article is to develop a physico-mathematical model for determining the direction to point sources of gamma radiation using a spherical absorber.

\section{Model development}

Physical part of the model for determining the direction in space to point sources of gamma radiaion, including pulsed ones, consists in the specific placement of detectors in the spherical absorber and using of ratios for information [5] received from the detectors that are proportional to thickness of the absorber in the path of gamma radiation. Detection units with the absorber were located fixed, which made it possible to measure the direction to the pulsed sources of gamma radiaion. Sizes of the detection units are $20 \mathrm{~mm}$ in length and $10 \mathrm{~mm}$ in diameter, which is due to the placement $4 \times 4 \times 2 \mathrm{~mm}$ telurid-cadmium sensors in them together with a preamplifier of $8 \times 8 \times 1,5 \mathrm{~mm}$ dimensions under a layer of steel with sickness $d=10 \mathrm{~mm}$. The sizes of the sensors with CdTe can be reduced, which makes it possible to determine the direction to the sources of gamma radiaion at a shorter distance, because for the point sources of gamma radiaion this distance should be approximately 10 times exceed the dimensions of the sources of gamma radiaion and the sensor [6]. For example, the authors of this article created CdTe sensors with the size of $1 \times 1 \times 1 \mathrm{~mm}^{3}$, which allows to reduce the size of the detector in the spherical absorber.

Accuracy of measuring the direction to the sources of gamma radiaion depends on accuracy of measuring the signal levels and gradient of the thickness variation of the absorber depending on the angle between the source and specified coordinate, which is from $10 \mathrm{~mm}$ to $86 \mathrm{~mm}$ for physical-mathematical model of the spherical absorber. The diameter of the selected sphere was $100 \mathrm{~mm}$, which is explained by the sufficient sensitivity of the detection units for the constant point sources of gamma radiaion and provides the possibility of determining the impulse point sources of gamma radiaion. The sensors were placed in the absorber at a distance of one centimeter from its surface

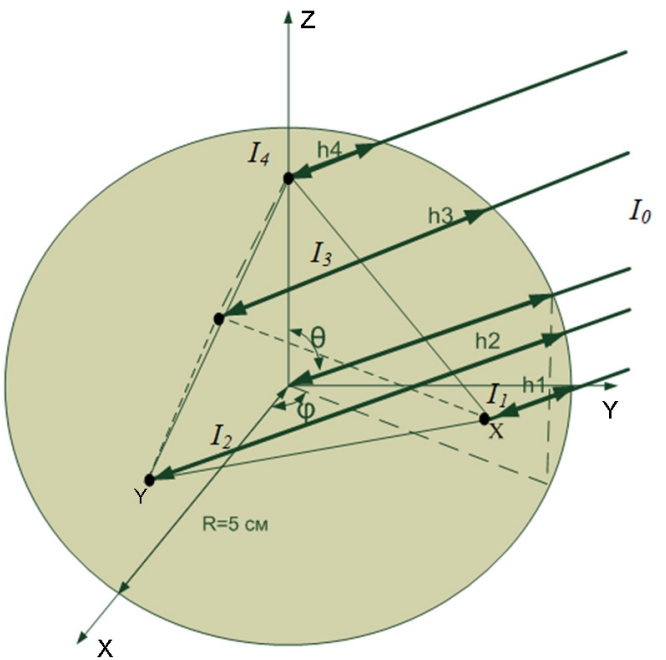

Fig. 1. General view of location of detectors in a spherical absorber and thickness of absorber $h$ in front of the detectors in the direction to the source of gamma radiation.

at the vertices of regular pyramid, which ensures their maximum distance from each other (Fig. 1).

To determine the information coming from the detector, the law of exponential attenuation of gamma radiation in materials [7] is applied:

$$
I_{i}=I_{0} \times e^{-\mu h_{i}}
$$

where $I_{i}$-intensity of gamma radiation that reaches the $i$ detector through the absorber $h_{\text {, }}$, $\mu$ - is the linear absorber attenuation coefficient, $\mathrm{cm}^{-1}$.

The ratio of information [5] received from one detector to another will be similar to the ratio of gamma-ray transmittance ratios, which are the ratio of $I / I_{0}$ from formula (1). In development of the mathematical model for determining the direction in space to the point sources of gamma radiaion, including pulsed sources, the main task was to obtain formulas for finding the distance from an arbitrary point of the regular pyramid to an arbitrary point of the surface of the sphere. The solution of this problem is carried out as follows.

Vector $\vec{v}=\left[v_{x}, v_{y}, v_{z}\right]$ determines the direction in space (Fig. 2a). Suppose that the length of this vector is equal to one, that is $v_{x}^{2}+v_{y}^{2}+v_{z}^{2}=1$. The coordinates of this vector can be written in spherical coordinates [8]:

$$
\vec{v}=[\cos \phi \times \sin \theta, \sin \phi \times \sin \theta, \cos \theta],
$$

where $\varphi-$ is angle from $0^{\circ}$ to $360^{\circ}$ in $x y$ plane, $\theta$ - is angle from $0^{\circ}$ to $180^{\circ}$ along $z$ axis.

Let us find the coordinates of the tetrahedron vertices. To this end, we note first of all that all its vertices lie on a sphere of radius $r=4 \mathrm{~cm}$, specified by us for the maximum distance, with the center at the origin, that is the 


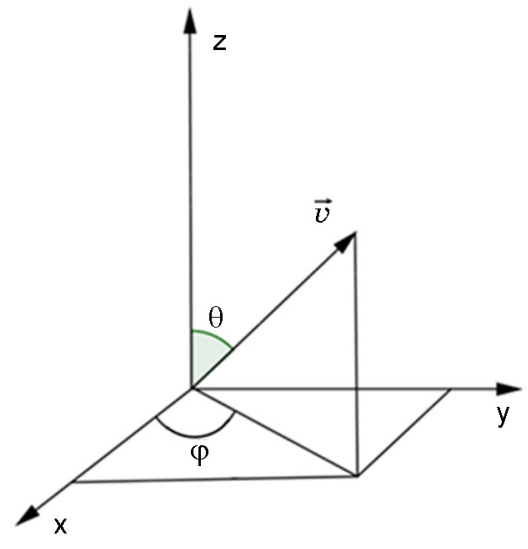

a)

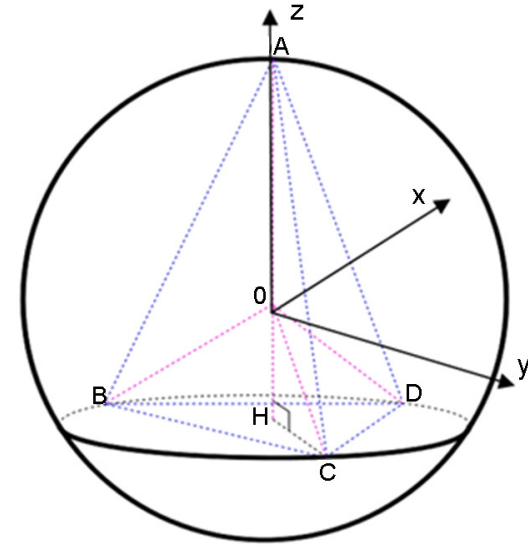

b)

Fig. 2. $\mathrm{a}$ - general view of vector that determines the direction in spherical coordinates; $\mathrm{b}$ - general view of specified points on sphere with radius $r=4 \mathrm{~cm}$.

coordinates of these points must satisfy the sphere equation $x^{2}+y^{2}+z^{2}=4^{2}$ [9]. Binding of the detector's location points to the coordinate system is set as follows. We start with a point that is on $z$ axis. Let's call this point $A(0,0,4)$. Then the point that is under $x$ axis, $D\left(d_{x}, 0, d_{z}\right)$. Let's call two remaining points $B\left(b_{x}, b_{y}, b_{z}\right), C\left(c_{x}, c_{y}\right.$, $c_{z}$ ) (Fig. 2b).

We note that $d_{z}=b_{z}=c_{z}<0$. In addition, due to the symmetry, because of $y$-coordinate of the point $D$ is equal to $0, b_{x}=c_{x}$ and $b_{y}=-c_{y}$. To simplify the calculations we designate the edge of the tetrahedron as $A B=A C=A D=B C=C D=B D=a, \quad$ and radius of the circle, on which the vertices of the tetrahedron are located, $r=4$ (Fig. 2b). Triangle $\triangle B C D$ is equilateral, that is, all sides of it are equal, and all angles are equal to $60^{\circ}$. Point $H$ is the intersection of medians and bisectors, that is, angle $\angle H C B=\angle H C D=\angle H D C=30^{\circ}$ .Triangle $\triangle H C D$ is isosceles $(H C=H D)$, angle $\angle C H D=120^{\circ}$. Using the cosine theorem, we find:

$$
\begin{aligned}
C D^{2}= & H C^{2}+H D^{2}-2 H C \times H D \times \cos 120^{\circ}, \\
& a^{2}=2 H C^{2}-2 H C^{2} \times \cos 120^{\circ}= \\
& =2 H C^{2}\left(1-\left(-\frac{1}{2}\right)\right)=3 H C^{2}
\end{aligned}
$$

then $H C^{2}=\frac{a^{2}}{3}$.

In this way, $H C=H D=H B=\frac{a}{\sqrt{3}}$. Let's consider $\triangle A H C$. The hypotenuse is $A C=a$, therefore angle $\angle H A C=\alpha$ is such, that $\sin \alpha=\frac{1}{\sqrt{3}}$, $\cos \alpha=\sqrt{\frac{2}{3}}$. Triangle $\triangle A O C$ is isosceles, there- fore $\angle O A C=\angle O C A=\alpha$. This implies that $\angle A O C=180^{\circ}-2 \alpha$. From the cosine theorem for triangle $\triangle A O C$ we obtain that:

$$
\begin{aligned}
& a^{2}= \\
& r^{2}+r^{2}-2 r \times r \times \cos \left(180^{\circ}-2 \alpha\right)= \\
& 2 r^{2}(1+\cos 2 \alpha)=2 r^{2}\left(1+\cos ^{2} \alpha-\sin ^{2} \alpha\right),
\end{aligned},
$$

then $a^{2}=2 r^{2}\left(1+\frac{2}{3}-\frac{1}{3}\right)=\frac{8 r^{2}}{3}$.

In this way, $a=\frac{r \sqrt{8}}{\sqrt{3}}$ (a known value, since the radius $r=4$ is known). We know also segments $O C$ and $H C$, therefore, it is easy to find $O H=-d_{z}=-b_{z}=-c_{z}$. Indeed, according to the Pythagorean theorem,

$$
\begin{gathered}
O H^{2}=O C^{2}-H C^{2}= \\
=r^{2}-\frac{a^{2}}{3}=r^{2}-\frac{8 r^{2}}{9}=\frac{r^{2},}{9}
\end{gathered}
$$

then $O H=\frac{r}{3}$.

Since point $D\left(d_{x}, 0,-\frac{r}{3}\right)$ is on the sphere with the center at the origin and has radius $r$, the coordinates of this point must satisfy the sphere equation, that is $d_{x}^{2}+\left(\frac{r}{3}\right)^{2}=r^{2}$. This means, that $d_{x}=\frac{r \sqrt{8}}{3}$. In this way, the point $D\left(\frac{r \sqrt{8}}{3}, 0,-\frac{r}{3}\right)=\left(\frac{4 \sqrt{8}}{3}, 0,-\frac{4}{3}\right)$. 
Triangle $\triangle B C D$ lies in a plane parallel to $x y$ plane, it is equilateral, and vertex $D$ is located under the $x$ axis. This means that vertices B, C must be located symmetrically about $x$ axis. That is $b_{y}=-c_{y}, b_{x}=c_{x}$. Since $B C=a=\frac{2 r \sqrt{2}}{\sqrt{3}}$, then $b_{y}=-c_{y}=\frac{B C}{2}=\frac{r \sqrt{2}}{\sqrt{3}}$. We use once again the fact, that points $B$ and $C$ are on the sphere and we find $b_{x}=c_{x}$ $: b_{x}^{2}=r^{2}-b_{y}^{2}-b_{z}^{2}=r^{2}-\frac{2 r^{2}}{3}-\frac{r^{2}}{9}=\frac{2 r^{2}}{9}$. And therefore, $b_{x}=c_{x}=-\frac{r \sqrt{2}}{3}$. In general:

$$
\begin{gathered}
\mathrm{A}(0,0, \mathrm{r})=(0,0,4) ; \\
B\left(-\frac{r \sqrt{2}}{3}, \frac{r \sqrt{2}}{\sqrt{3}},-\frac{r}{3}\right)=\left(-\frac{4 \sqrt{2}}{3}, \frac{4 \sqrt{2}}{\sqrt{3}},-\frac{4}{3}\right) ; \\
C\left(-\frac{r \sqrt{2}}{3},-\frac{r \sqrt{2}}{\sqrt{3}},-\frac{r}{3}\right)=\left(-\frac{4 \sqrt{2}}{3},-\frac{4 \sqrt{2}}{\sqrt{3}},-\frac{4}{3}\right) ; \\
D\left(\frac{2 r \sqrt{2}}{3}, 0,-\frac{r}{3}\right)=\left(\frac{8 \sqrt{2}}{3}, 0,-\frac{4}{3}\right) .
\end{gathered}
$$

That is, when the coordinates of the vertices are known, we can find the distance from the vertex to any point in the sphere which has radius $R$. We derive a general formula for the distance, which can be applied to any of the points. The line that passes through point $P\left(p_{x}, p_{y}, p_{z}\right)$ in the direction of vector $\vec{v}=\left[v_{x}, v_{y}, v_{z}\right]$; is specified by the following parametric equations [11]:

$$
\left\{\begin{array}{l}
x(t)=p_{x}+t v_{x}, \\
y(t)=p_{y}+t v_{y}, \\
z(t)=p_{z}+t v_{z}, \ldots \ldots t \in R .
\end{array}\right.
$$

In order to write these equations in vector form, let's denote $\vec{p}=\left[p_{x}, p_{y}, p_{z}\right]$ and $\overrightarrow{r(t)}=[x(t), y(t), z(t)]$, then $\overrightarrow{r(t)}=\vec{p}+t \vec{v}$.

We substitute into the formula the coordinates of the point, which is located on the sphere of radius $r=4$, therefore we will assume that the distance from the origin to the point $\vec{p}=\sqrt{p_{x}^{2}+p_{y}^{2}+p_{z}^{2}}=r=4$. Coordinates $(x, y, z)$ of the intersections of the straight line (3) with the sphere $x^{2}+y^{2}+z^{2}=R^{2}$ must satisfy both equations. We substitute the expres- sions for $x(t), y(t), z(t)$ in the sphere equation and find the value of the parameter $t$ :

$$
\begin{gathered}
\left(p_{x}+t v_{x}\right)^{2}+\left(p_{y}+t v_{y}\right)^{2}+\left(p_{z}+t v_{z}\right)^{2}=R^{2}, \\
t^{2}+2 t(\vec{p} \vec{v})-\left(R^{2}-r^{2}\right)=0 .
\end{gathered}
$$

The last equation is a quadratic equation with respect to $t$. Using the formula for roots of the quadratic equation, we find two solutions:

$$
t_{1,2}=-(\vec{p} \vec{v}) \pm \sqrt{\left((\vec{p} \vec{v})^{2}+R^{2}-r^{2}\right)}
$$

In last formula $(\vec{p} \vec{v})=p_{x} v_{x}+p_{y} v_{y}+p_{z} v_{z}$ is a scalar product of two vectors in three-dimensional space. The coordinates of the intersection points (there are always two of them) are obtained by substituting the values of the parameter $t_{1,2}$ into the straight line equation

$$
\left\{\begin{array}{l}
x\left(t_{1,2}\right)=p_{x}+t_{1,2} v_{x} \\
y\left(t_{1,2}\right)=p_{y}+t_{1,2} v_{y} \\
z\left(t_{1,2}\right)=p_{z}+t_{1,2} v_{z}
\end{array}\right.
$$

Let's call these two intersection points $Q_{1,2}\left(x\left(t_{1,2}\right), y\left(t_{1,2}\right), z\left(t_{1,2}\right)\right)$. Note that equation (3) is a parametric equation that specifies a straight line, while equation (4) specifies three scalar values -the coordinates of a point in the three-dimensional space. Distance from point $P$ to point $Q_{1,2}$ is calculated as the length of the corresponding vectors between the points $P$ and $Q_{1,2}$ [9]:

$$
\overrightarrow{P Q_{1,2}}=\sqrt{\left(t_{1,2} v_{x}\right)^{2}+\left(t_{1,2} v_{y}\right)^{2}+\left(t_{1,2} v_{z}\right)^{2}}=\left|t_{1,2}\right| .
$$

From two points in which the line intersects the sphere, we choose the one we "meet first" when moving from the vertices of the tetrahedron in the specified vector direction. To do this, we choose the larger value of the parameter $t$, that is:

$$
\left|\overrightarrow{P Q}_{1}\right|=-(\vec{p} \vec{v})+\sqrt{\left((\vec{p} \vec{v})^{2}+R^{2}-r^{2}\right)} .
$$

In this way, if there is a known direction $\vec{v}=\left[v_{x}, v_{y}, v_{z}\right]$, then substituting the coordinates of the vertices of the tetrahedron $\vec{p}\left(p_{x}, p_{y}, p_{z}\right)$, the spheres radii $R=5, r=4$ into the formula (5), we calculate the distance from the vertices to the sphere. Using formula (5), a physico-mathematical model of the spherical absorber with four detectors was developed, three of which were located at the vertices of the equilateral triangle on $1.3 \mathrm{~cm}$ offset from diametrical plane of the sphere, and their plane was orthogonal to the force of gravity vector and axis vector $z$, and one vertex $D$ was under $x$ axis. This location of the detectors determined the origin and allowed the binding of the developed device in space, which allows 


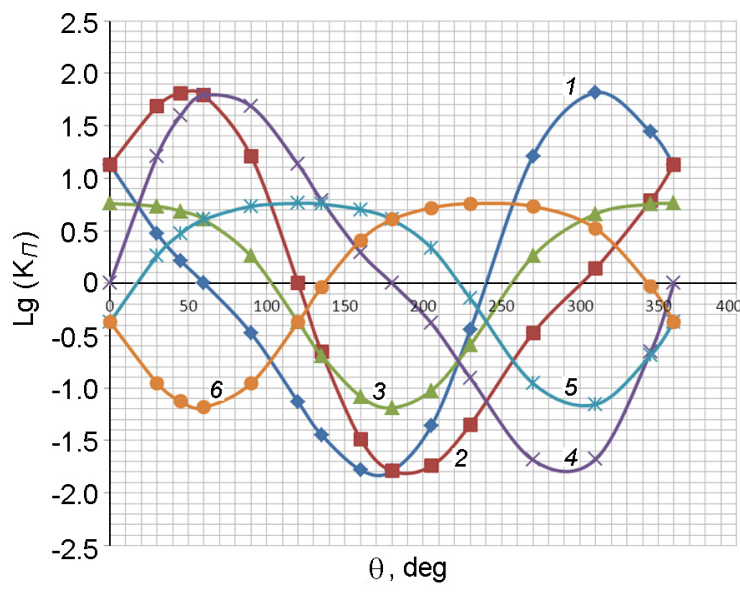

Fig. 3. Theoretically calculated dependences of decimal logarithms coefficients of proportionality $C_{P}$ on angle $\varphi=0^{\circ}-360^{\circ}\left(\theta=90^{\circ}\right)$ for direction to sources of gamma radiation.

comparison of the theoretically calculated and practical data. At the calculations, angle $\theta=90^{\circ}$ is not changed, and angle $\varphi$ varied from $0^{\circ}$ to $360^{\circ}$ in increments of $15^{\circ}$. Based on the distances found, the coefficients of proportionality $C_{P}$ were calculated according to the formula:

$$
C_{P}=e^{-\mu\left(h_{x}-h_{y}\right)}
$$

where $h_{x}$ - absorber thickness in front of detector $x$ in a spherical absorber, $\mathrm{cm}$;

$h_{\mathrm{y}}$ - absorber thickness in front of other detector $y$ in a spherical absorber, $\mathrm{cm}$.

By the values of the coefficients of proportionality calculated by formula (6), their decimal logarithms were determined and their dependence on angle $\varphi$ (Fig. 3) was constructed, indicating the correspondence to each direction in the space of a certain set of six $C_{P}$.

In this way, the physico-mathematical model with angle $\theta=90^{\circ}$ and $\varphi=0^{\circ}-360^{\circ}$ was developed and worked out to determine the direction to the point sources of gamma radiation in space with the use of spherical absorber.

\section{Conclusions}

1. Thus, we propose the model of a device for determining the direction to a gamma source using a spherical absorber with sensors which are located at the vertices of a regular pyramid to provide the greatest gradient of the absorber thickness, under the absorber layer thickness of $1 \mathrm{~cm}$.

2. Depending on angle to the source of gamma radiation in space, thickness of the spherical absorber in the direction to gamma radiation from the surface of the sphere to the sensor and proportionality coefficients representing the ratio of transmittance coefficients of one sensor to the other are determined on the basis of the proposed physico-mathematical model.

\section{Reference}

1. V.B. Bolshakov, N.I. Kosach, Metrol. Devices, 5, 49 (2014).

2. Z.V. Bilyk, E. F. Voronkin, A.N. Grigoryev at al., Functional Materials,21, 352 (2014).

3. Patent No.2386146 (2010), Ukrainian.

4. Z.V. Bilyk, E. F. Voronkin, A.N. Grigoryev at al., Functional Materials,24, 628 (2017).

5. Patent No.85910 (2013), Ukrainian.

6. I.Y. Cherniavskiy, V.V. Maruschenko, I.M. Martynuyk, "Vijs'kova dozimetrija" "KhPI", Kharkiv, 560 (2012).

7. G.F. Knoll, Radiation Detection and Measurement. Wiley, New York, (1979).

8. V.A. Il'in, E.G. Poznjak, "Analiticheskaja Geometrija: Kurs Vysshej Matematiki i Matematicheskoj Fiziki” Science - Fizmatlit, Moscow, (1999).[ in Russian]

9. I.I. Privalov, "Analiticheskaja Geometrija" Science - Fizmatlit, Moscow, (1999). [ in Russian] 